\title{
ASSESSMENT OF CARDIOMETABOLIC RISK FACTORS AMONG LOCAL POPULATION OF NATIONAL CAPITAL REGION
}

\author{
PREETI SHARMA ${ }^{1 *}$, PRADEEP KUMAR ${ }^{1}$, RACHNA SHARMA ${ }^{2}$, SATYA PRAKASH ${ }^{3}$
}

${ }^{1}$ Department of Biochemistry, Santosh Medical College and Hospital, Ghaziabad, Uttar Pradesh, India. ${ }^{2}$ Department of Biochemistry, TSM Medical College and Hospital, Lucknow, Uttar Pradesh, India. ${ }^{3}$ Department of Biochemistry, B. R. D. Medical College, Gorakhpur, Uttar Pradesh, India. Email: Prcdri2003@yahoo.co.in

Received: 20 March 2017, Revised and Accepted: 03 May 2017

ABSTRACT

Objective: In view of marked accentuations in cardiometabolic diseases in developing countries such as India, we aimed to conduct a cross-sectional study analyzing the prevalence of cardiometabolic risk factors in local population of Ghaziabad.

Methods: The study is descriptive, random sample survey, and cross-sectional study. The study was carried out at Santosh Medical College, Ghaziabad, on 350 participants between the age group 18-70 years. After taking the informed consent, they were included in the study. The variables recorded were clinical history, all risk factors of cardiovascular disease including blood pressure, body mass index, waist circumference, blood sugar and serum lipid levels, cigarette use, and dietary habit.

Result: Our study shows that the high prevalence of multiple risk factors in a general population with as many as $70 \%$ of the participants had metabolic syndrome. Among individually studied groups, obesity was the most common followed by dyslipidemia then diabetes and hypertension and the least prevalent was smoking. Females were more commonly affected than males by dyslipidemia and obesity, probably due to physical inactivity coupled with unhealthy diet and lifestyle.

Conclusion: There is the higher prevalence of cardiometabolic risk factors among the population making the individuals prone to associated spontaneous coronary artery dissection and their predisposition. Therefore, timely detection of cardiometabolic factors and appropriate interventions may be of prime concern.

Keywords: Cardiometabolic risk factors, Dyslipidemia, Risk to associated spontaneous coronary artery dissection.

(C) 2017 The Authors. Published by Innovare Academic Sciences Pvt Ltd. This is an open access article under the CC BY license (http://creativecommons. org/licenses/by/4. 0/) DOI: http://dx.doi.org/10.22159/ajpcr.2017.v10i8.18588

\section{INTRODUCTION}

One of the major causes of mortality and morbidity, the cardiometabolic diseases are emerging as an important health concern in developing and developed countries. Predominantly, they are lifestyle-related diseases having various modifiable and non-modifiable risk factors. Smoking, sedentary lifestyle, psychosocial stress, and obesity are modifiable risk factors while diabetes mellitus, hypercholesterolemia, and hypertension metabolic syndrome are non-modifiable risk factors [1]. These factors if not timely checked or controlled may lead to ischemic heart disease secondary to atherosclerotic coronary vascular disease [1-3]. Besides all these parameters, homocysteine level, elevated coronary artery calcium, marked carotid intima-media thickness, aortic pulse wave velocity as a measure of arterial stiffness, elevated C-reactive protein, elevated lipoproteins(a), fibrinogen, plasminogen activator inhibitor, platelet count, lipoprotein-associated phospholipase A2 are few other non-conventional markers but their clinical relevance has not been established [4]. There are substantial variations present at country, regional, and urban-rural levels due to lifestyle variations such as dietary factors, physical activity, and smoking. In India, also a number of studies conducted and have shown the prevalence of obesity, hypertension, hypercholesterolemia, and diabetes in urban as compared to rural population [5,6]. Various ethnic and sociocultural differences are responsible for this vast geographical variation in cardiometabolic risk factors. Due to marked accentuation in cardiometabolic diseases in developing countries such as India, it is necessary to study the various cardiometabolic risk factors in a local population such as Ghaziabad as there is no population-based crosssectional study analyzing the prevalence of cardiometabolic risk factors in this part of the world.

\section{METHODS}

It was a hospital-based cross-sectional study carried out at Santosh Medical College and Hospital, Ghaziabad during the past 2 years from 2015 to 2016. Total 350 participants between the age group 18 and 70 years were included in the study after receiving their written consent. Following are the inclusion criteria for selection of participants:

Waist circumference - $>90 \mathrm{~cm}$ for males and $>80 \mathrm{~cm}$ for females. Dyslipidemia - Triglycerides $>150 \mathrm{mg} / \mathrm{dl}$ and are on no specific medication. High-density lipoprotein cholesterol (HDLc): $<40$ and $50 \mathrm{mg} / \mathrm{dl}$, respectively, for males and females with no medication. Hypertension: Blood pressure (BP) $\geq 130 \mathrm{~mm} \mathrm{Hg}$ and systolic BP $\geq 85$ with no specific medication. Fasting plasma glucose (FPG) $\geq 100 \mathrm{mg} / \mathrm{dl}$, post-prandial plasma glucose $140-199 \mathrm{mg} / \mathrm{dl}$ or hemoglobin A1c - 5.7$6.4 \%$. All diabetic patients were irrespective of specific treatment for diabetes. All patients who were diagnosed as having metabolic syndrome as per Asian Specific Harmonized Criteria.

Patients suffering from coronary artery disease and atherosclerotic coronary vascular diseases, chronic granulomatous diseases such as tuberculosis and leprosy or any oncological diseases, hepatic impairment and thyroid disorder were excluded from the study.

The participants were evaluated and selected by detailed medical history, physical examination, systemic examination, or routine investigations to rule out any underlying disease.

All patients were subjected to measurement of height, weight, body mass index (BMI), and waist circumference and waist-hip ratio [6]. FPG 
estimation was done by glucose oxidase and peroxidase, i.e., glucose oxidase-peroxidase method [7]. Electrocardiogram was done to rule out coronary artery disease/atherosclerotic coronary vascular disease. Total serum cholesterol estimation was done using cholesterol oxidasephenol 4-aminophenazone peroxidase method [8]. Triglycerides (TGs) estimation was done by GPO-Trinder method [8]. Very low-density lipoprotein cholesterol (LDLC) and LDLc concentration estimation were done using Friedwald's formula. HDLc estimation was done by polyethylene glycerol methyl ether coupled classic precipitation method [8]. All data were analyzed and reported as mean with standard using group and descriptive statistics using SPSS database. Independent Student's t-test was done to find out the significance ( $p$ value) between data of male and female test group. $p<0.05$ was considered as statistically significant.

\section{RESULTS}

The participants consisted of 171 males and 179 females with the prevalence of $48.86 \%$ and $51.14 \%$, respectively. Largest number of participants of studied population belongs to the age group 40-49 years of age. The prevalence of various cardiometabolic risk factors in the study group was represented by metabolic syndrome which is affecting $245(70 \%)$ out of participants and is the most important risk factor. Next, the most common factor was obesity with $56.9 \%$ prevalence including 199 out of 350 people, followed by dyslipidemia, diabetes, and hypertension with $51.1 \%, 45.1 \%$, and $44.9 \%$ prevalence, respectively. The least prevailing factor was smoking with $4.3 \%$ (Table 1).

Table 2 illustrates the various risk factors as variables studied among 350 participants. The analyzed variables were studied in both men and women. The most commonly encountered risk factor among study participants was raised total cholesterol at $247.8 \pm 57.89$ in women and $247.3 \pm 58.82$ among men. The difference between the two groups is not statistically significant $(0.957)$. Among other variables, the difference in prevalence of obesity (BMI $>30 \mathrm{~kg} / \mathrm{m}^{2}$ ) and smoking were statistically significant at $\mathrm{p}=0.023$ and 0.003 , respectively.

Table 1: The prevalence of various cardiometabolic risk factors in the study group of 350 patients

\begin{tabular}{ll}
\hline Variables & Number of participants (\%) \\
\hline Obesity & $199(56.9)$ \\
Diabetes & $158(45.1)$ \\
Hypertension & $157(44.9)$ \\
Dyslipidemia & $179(51.1)$ \\
Metabolic syndrome & $245(70)$ \\
Smoking & $15(4.3)$ \\
\hline
\end{tabular}

Table 3 is showing the prevalence of various risk factors with obesity. It is seen that the prevalence of raised cholesterol at $234.68 \pm 33.51$ in obese participants and $274.27 \pm 84.10$ in non-obese participants was the most commonly seen risk factor. The difference between the two groups was statistically significant $(\mathrm{p}=0.000)$. The difference in prevalence of central abdominal obesity with waist circumference $>90 \mathrm{~cm}(0.000)$ in men and $>80 \mathrm{~cm}$ in women along with metabolic syndrome was also significant $(0.000)$.

\section{DISCUSSION}

It was planned to study the prevalence of major modifiable and non-modifiable factors in the general population, attending hospital outpatient department in Ghaziabad. The study included 350 participants of 18-70 years of age; the largest group was represented by 40-49 years. An important focus of recent studies is the changing trends in cardiovascular risk factors. In the past 30 years, the prevalence of hypertension and hypercholesterolemia has doubled while that of diabetes has tripled. In our study, we found metabolic syndrome as the most prevalent risk factor affecting 245 (70\%) study participants out 350 while smoking was the least prevalent risk factor including just 15 (4.3\%) people from our study population. We found the prevalence of hypertension, dyslipidemia, and diabetes to be $44.9 \%$, $51.1 \%$, and $45.1 \%$, respectively (Table 1 ). The results obtained are having higher values than Jaipur Heart Watch-6 study which reported the prevalence of hypertension, dyslipidemia (TG $\geq 200 \mathrm{mg} / \mathrm{dl}$ ) and diabetes to be $36 \%, 25.8 \%$, and $19.2 \%$, respectively. The Jaipur Heart Watch studies in India evaluated multiple cardiovascular risk factors in urban middle-class participants using multiple cross-sectional study design over a 20 year period from 1991 to 2010 [9]. During the period, the prevalence of smoking declined, no chance in hypertension was observed while all other risk factors such as obesity, truncal obesity, hypercholesterolemia, diabetes, and metabolic syndrome increased significantly. The data was analyzed by plotting graph of individual risk factors among male and female groups. More number of females was found to be associated with raised total cholesterol as compared to males. Data on hypercholesterolemia in our study reveal consistency with India Migratory Study including 1983 participants [10]. Obesity in our study was considered as patients having BMI $\geq 30 \mathrm{~kg} / \mathrm{m}^{2}$ was $35.04 \pm 4.02$ (Table 2). When the difference in the mean and standard deviation (SD) assessed in between male and female group, it was found statically significant $(0.023)$. On plotting difference in mean and SD, between male and female group across other parameters of obesity, namely, BMI $\geq 25 \mathrm{~kg} / \mathrm{m}^{2}$ but $<30 \mathrm{~kg} / \mathrm{m}^{2}$ and waist to hip ratio (men >0.9; women $>0.8 \mathrm{~cm}$ ), it was found that female group had higher values than male group for the risk factor considered. The difference in their prevalence was however not statistically significant ( $p>0.05)$. All other risk factors of importance and their respective prevalence in obese participants $(\mathrm{n}=191)$ were studied and compared with nonobese study participants $(\mathrm{n}=151)$. It was seen that the prevalence of

Table 2: Comparative analysis of various cardiometabolic risk factors in men and women

\begin{tabular}{|c|c|c|c|c|}
\hline \multirow[t]{2}{*}{ Variables } & \multicolumn{3}{|l|}{ Mean \pm SD } & \multirow[t]{2}{*}{ p value } \\
\hline & Total $(n=350)$ & Women $(n=179)$ & Men (n=171) & \\
\hline Obesity BMI $\geq 25 \mathrm{~kg} / \mathrm{m}^{2}$ and $<30 \mathrm{~kg} / \mathrm{m}^{2}$ & $27.18 \pm 1.33$ & $27.22 \pm 1.23$ & $27.14 \pm 1.42$ & 0.701 \\
\hline $\mathrm{BMI} \geq 30 \mathrm{~kg} / \mathrm{m}^{2}$ & $35.04 \pm 4.02$ & $35.63 \pm 4.17$ & $34.32 \pm 3.72$ & 0.023 \\
\hline $\mathrm{W}: \mathrm{H}$ ratio $($ men $>0.9$; women $>0.8 \mathrm{~cm})$ & $0.99 \pm 0.53$ & $1 \pm 0.05$ & $0.99 \pm 0.05$ & 0.337 \\
\hline Diabetes (FBS $\geq 100 \mathrm{mg} / \mathrm{dl})$ & $164 \pm 72.02$ & $161.1 \pm 72$ & $167.4 \pm 72.3$ & 0.538 \\
\hline $\begin{array}{l}\text { HTN (known hypertensive; systolic BP } \geq 130 \mathrm{mmHg} \text {, and diastolic } \\
\mathrm{BP} \geq 85 \mathrm{mmHg} \text { ) }\end{array}$ & $147.2 \pm 80.12$ & $148.1 \pm 19.5$ & $146.2 \pm 16.6$ & 0.458 \\
\hline Dyslipidemia (Total cholesterol $\geq 200 \mathrm{mg} / \mathrm{dl}$ ) & $247.6 \pm 58.11$ & $247.8 \pm 57.9$ & $247.3 \pm 58.8$ & 0.957 \\
\hline $\mathrm{TGL} \geq 150 \mathrm{mg} / \mathrm{dl}$ & $224.4 \pm 87.94$ & $221.5 \pm 77.3$ & $227.5 \pm 98.5$ & 0.656 \\
\hline $\mathrm{LDL} \geq 130 \mathrm{mg} / \mathrm{dl}$ & $168.6 \pm 33.44$ & $171.2 \pm 36.8$ & $165.3 \pm 28.6$ & 0.318 \\
\hline $\mathrm{HDL}<40 \mathrm{mg} / \mathrm{dl}$ for male; $<50$ for female & $47.15 \pm 10.12$ & $39.01 \pm 5.92$ & $34.33 \pm 4.41$ & 0.631 \\
\hline Metabolic syndrome & $1.3 \pm 0.459$ & $1.26 \pm 0.44$ & $1.34 \pm 0.48$ & 0.119 \\
\hline Smokers & $1.96 \pm 0.2$ & $1.99 \pm 0.11$ & $1.92 \pm 0.27$ & 0.003 \\
\hline
\end{tabular}

HTN: Hypertension, HDL: High-density lipoprotein, LDL: Low-density lipoprotein, BP: Blood pressure, FBS: Fasting blood sugar, SD: Standard deviation, BMI: Body mass index 
Table 3: Comparative analysis of various clinical and biochemical parameters in obese patients

\begin{tabular}{|c|c|c|c|}
\hline \multirow[t]{2}{*}{ Variables } & \multicolumn{2}{|c|}{ Mean \pm SD } & \multirow[t]{2}{*}{ p value } \\
\hline & Obese & Non-obese & \\
\hline Age & $46.63 \pm 12.07$ & $45.61 \pm 13.54$ & 0.459 \\
\hline Men $>90 \mathrm{~cm}$ & $108.46 \pm 12.52$ & $99.85 \pm 7.31$ & 0.000 \\
\hline Women $>80 \mathrm{~cm}$ & $108.27 \pm 12.60$ & $99.13 \pm 7.49$ & 0.000 \\
\hline $\mathrm{W}: \mathrm{H}$ ratio $($ men $>0.9 \mathrm{~cm}$; women $>0.8 \mathrm{~cm})$ & $1.0 \pm 0.47$ & $1 \pm 0.47$ & 0.976 \\
\hline Diabetes (known diabetics of FBS $\geq 100 \mathrm{mg} / \mathrm{dl}$ ) & $155.69 \pm 65.51$ & $174.41 \pm 78.52$ & 0.066 \\
\hline HTN (known hypertensives/systolic BP $\geq 130 \mathrm{mmHg}$, diastolic $\mathrm{BP} \geq 85 \mathrm{mmHg}$ ) & $147.58 \pm 19.90$ & $146.75 \pm 15.91$ & 0.747 \\
\hline Dyslipidemia (total cholesterol $\geq 200 \mathrm{mg} / \mathrm{Hg}$ ) & $234.68 \pm 33.51$ & $274.27 \pm 84.10$ & 0.000 \\
\hline $\mathrm{TGL} \geq 150 \mathrm{mg} / \mathrm{dl}$ & $228.34 \pm 92.21$ & $216.95 \pm 79.60$ & 0.420 \\
\hline $\mathrm{LDL} \geq 130 \mathrm{mg} / \mathrm{dl}$ & $165.82 \pm 32.46$ & $175.42 \pm 35.25$ & 0.137 \\
\hline HDL (<40 mg/dl; women <50 mg/dl) & $33.76 \pm 4.89$ & $34.77 \pm 4.00$ & 0.387 \\
\hline Metabolic syndrome & $1.21 \pm 0.41$ & $1.42 \pm 0.50$ & 0.000 \\
\hline Smokers & $1.96 \pm 0.20$ & $1.95 \pm 0.21$ & 0.778 \\
\hline
\end{tabular}

raised total cholesterol at $234.68 \pm 33.51$ in obese participants and $274.27 \pm 84.10$ in non-obese participants (Table 3 ) was most commonly seen risk factor. The difference in mean between the two groups was statistically significant $(\mathrm{p}=0.000)$. The difference in means of prevalence of central abdominal obesity with waist circumference $>90 \mathrm{~cm}(0.000)$ in men and $>80 \mathrm{~cm}$ in women along with metabolic syndrome was also statistically significant $(0.000)$ (Table 3$)$. Similar results were reported by DS Prasad et al. [10]. Numerous other epidemiological studies also show that BMI is a powerful predictor of Type 2 diabetes, hypertension, hypercholesterolemia, and heart diseases [11-15].

\section{CONCLUSION}

The study shows the higher prevalence of multiple risk factors in a general population with as many as $70 \%(\mathrm{n}=245)$ participants were having metabolic syndrome. Among the groups, obesity was the most common followed by dyslipidemia then diabetes, hypertension, and least prevalent factor was smoking. Females were most commonly affected than males by dyslipidemia and obesity, probably due to physical inactivity coupled with unhealthy lifestyle. Therefore, Indians are at high risk for ASCVD and their predisposition. Early identification of cardiometabolic risk factors and appropriate intervention may be of primary importance in population.

\section{REFERENCES}

1. Iyengar SS, Puri R, Narasingan SN, Wangnoo SK, Mohan V, Mohan JC, et al. Lipid association of India expert consensus statement on management of dyslipidemia in Indians 2016: Part 1. J Assoc Phys India 2016;64 Suppl 3:7-52.

2. Fanty, Widayati A, Hendra P. Relationship of body fat percentage and APO B/APO A-1 ratio as cardiovascular risk marker in rural adults of Indonesia. Int J Pharm Pharm Sci 2017;9(2):114-6.

3. Pathak KY, Mohanan A, Acharya S, Mandavia D, Hemant R. Exploring visceral adiposity index as a predictor of visceral adiposity dysfunction and evaluating its performance in predicting hepatic insulin resistance in Indian Type 2 diabetes. Int J Pharm Pharm Sci 2016;8(8):297-301.
4. Yusuf S, Hawken S, Ounpuu S, Dans T, Avezum A, Lanas F, et al. Effect of potentially modifiable risk factors associated with myocardial infarction in 52 countries (the INTERHEART study): Case-control study. Lancet 2004;364(9438):937-52.

5. Shah A, Afzal M. Prevalence of diabetes and hypertension and association with various risk factors among different Muslim populations of Manipur, India. J Diabetes Metab Disord 2013;12:52

6. Joshi SR, Anjana RM, Deepa M, Pradeepa R, Bhansali A, Dhandania VK, et al. Prevalence of dyslipidemia in urban and rural India: The ICMR-INDIAB study. PLoS One 2014;9(5):e96808.

7. Garrow JS, Webster J. Quetelet's index (W/H2) as a measure of fatness. Int J Obes 1985;9(2):147-53.

8. Basak A. Development of a rapid and inexpensive plasma glucose estimation by two-point kinetic method based on glucose oxidaseperoxidase enzymes. Indian J Clin Biochem 2007;22(1):156-60.

9. Rifai N, Warnick GR, Remaley AT. Lipids, lipoproteins, apolipoproteins, and other cardiovascular risk factors. In: Burtis CA, Ashwood ER, Bruns DE, editors. Teitz Fundamentals of Clinical Chemistry. Pennsylvania: Saunders an Imprint of Elsevier Inc.; 2010. p. 422-4.

10. Tandon VR, Mahajan A, Sharma S, Sharma A. Prevalence of cardiovascular risk factors in postmenopausal women: A rural study. J Midlife Health 2010;1(1):26-9.

11. Kinra S, Bowen LJ, Lyngdoh $\mathrm{T}$, Prabhakaran D, Reddy KS, Ramakrishnan L, et al. Sociographic patterning of non-communicable diseases risk factors in rural India: A cross sectional study. BMJ 2010;341:c4974.

12. Prasad DS, Kabir Z, Dash AK, Das BC. Prevalence and risk factors for metabolic syndrome in Asian Indians: A community study from urban Eastern India. J Cardiovasc Dis Res 2012;3:e204-11.

13. Astrup A, Finer N. Redefining Type 2 diabetes: 'Diabesity' or 'obesity dependent diabetes mellitus'? Obes Rev 2000;1(2):57-9.

14. Ramchandran A, Snehalatha C, Baskar AD, Mary S, Kumar CK, Selvam S, et al. Temporal changes in prevalence of diabetes and impaired glucose tolerance associated with lifestyle transition occurring in the rural population in India. Diabetologia 2004;47:860-5.

15. Poirier P, Giles TD, Bray GA, Hong Y, Stern JS, Pi-Sunyer FX, et al. Obesity and cardiovascular diseases: Pathophysiology, evaluation and effect of weight loss. Arterioscler Thromb Vasc Biol 2006;26(5):968-76. 